\title{
QUANTIFYING THE RELATION BETWEEN PREDATOR-INDUCED BEHAVIOR AND GROWTH PERFORMANCE IN LARVAL ANURANS
}

\author{
Rick A. RelyeA ${ }^{1}$ AND EARl E. Werner \\ Department of Biology, University of Michigan, Ann Arbor, Michigan 48109 USA
}

\begin{abstract}
Because the nature and magnitude of species interactions are functions of the traits that species possess, understanding how individual traits affect performance is important to our understanding of community structure. To examine the relation between species traits and performance, we first assessed behavioral responses of two larval anurans to three predator species in the laboratory. We then correlated these responses with growth performance of the two anurans when they competed in the field. In the laboratory experiment, larval bullfrogs (Rana catesbeiana) and green frogs ( $R$. clamitans) exhibited no reduction in activity or spatial avoidance to bluegill sunfish (Lepomis macrochirus), moderate reductions in activity and spatial avoidance of mudminnows (Umbra limi), and large reductions in activity and spatial avoidance of larval dragonflies (Anax spp.). In the field experiment, these behavioral responses were directly related to corresponding reductions in growth of the anuran larvae. Thus, for both species, changes in growth in the field could be correlated to the behavioral responses observed in the laboratory. Further, proportional changes in behavior in the presence of the different predators appeared to be related to changes in competitive relations in the field.
\end{abstract}

Key words: Anax spp.; anuran behavior and growth; Lepomis macrochirus; predator induction; Rana catesbeiana; Rana clamitans; Umbra limi.

\section{INTRODUCTION}

A central goal of community ecology is to predict the consequences of species interactions for community structure. In order to predict the consequences of such interactions, we must understand the underlying mechanisms of the interactions (Schoener 1986, Tilman 1987, Werner 1998). These mechanisms, in turn, are largely functions of individual traits such as behavior, morphology, and life history. Thus, it is crucial to develop the quantitative relations between species' traits and performance in the field if we are going to be able to predict the consequences of species interactions. If particular traits critical to interactions are common to many taxa, then results from such studies may be generalizable to other communities (Werner 1998).

A useful experimental approach to quantifying the relation between species' traits and performance is to take advantage of species whose traits are phenotypically plastic. Traits of individuals can be altered by exposure to different environments and these individuals then subjected to interactions with other species. This approach allows us quantitatively to relate trait changes to consequences for species interactions. One problem with this approach is that important traits such as behavior are often very dynamic and difficult to

Manuscript received 14 October 1997; revised 27 July 1998; accepted 27 July 1998.

${ }^{1}$ Current address: Department of Biological Sciences, University of Pittsburgh, Pittsburgh, Pennsylvania 15260 USA. assess under field conditions. It would be useful, then, to assess if short-term measurements of behavioral responses or other trait changes conducted under controlled laboratory conditions offer any insight into species performance in the field when interacting with other species.

In this study, we examined the relation between short-term behavioral observations in the laboratory and performance under more natural conditions in the field. To accomplish this, we first conducted laboratory experiments examining the responses of two anuran larvae, bullfrogs (Rana catesbeiana) and green frogs (R. clamitans), to three potential predators. These predators, bluegill sunfish (Lepomis macrochirus), mudminnows (Umbra limi), and odonate larvae (Anax junius and A. longipes), are common predators found on the gradient of pond hydroperiod along which the two anuran larvae are distributed (Collins and Wilbur 1979, Werner and McPeek 1994, Wellborn et al. 1996). Because the three predators represent different risks to the anuran larvae (Werner and McPeek 1994; Relyea, unpublished manuscript), we expected that they would generate variation in the magnitude of the behavioral responses of the anuran larvae. We examined activity and spatial responses of the anurans, both of which are ubiquitous responses to predators (Sih 1987, Lima and Dill 1990, Werner 1992). Both of these behaviors also are related to a species' competitive ability and vulnerability to predators (Werner 1991; Werner and Anholt 1993; Relyea, unpublished manuscript). 
We then assessed the relation between behavioral responses measured in the laboratory and performance of the anuran larvae when competing under more natural conditions in the field. We hypothesized that the behavioral responses to predators would result in different growth responses and competitive performances. Competition studies conducted in the nonlethal presence of these predators in the field indicated that the behavioral responses in the laboratory were highly correlated with growth responses and relative competitive performance.

\section{Methods}

For both the laboratory and field experiments, we examined larval bullfrog and green frog responses to the absence and presence of different species of caged predators: Anax, Umbra, or Lepomis. Caged predators simulate predation risk without mortality to the experimental populations, since a major part of the predator cue is a water-soluble chemical (Kats et al. 1988, Werner 1991, McCollum and Van Buskirk 1996, Werner and Anholt 1996). Thus, this system provides the opportunity to examine competitive relations between the two anuran prey under a variety of predator combinations that should alter prey behavior in different ways.

\section{Laboratory experiments}

We collected multiple clutches of green frog eggs from the University of Michigan's E. S. George Reserve and bullfrog eggs from the Michigan Department of Natural Resources' Saline Fish Hatchery. We hatched the eggs and reared the tadpoles in small, predator-free wading pools for $\sim 3$ wk before the experiments were initiated. The experiments were conducted in plastic containers filled with $7 \mathrm{~L}$ of aged well water. Each container was equipped with a single predator cage, constructed of two wooden slats suspending a mesh bag in the container (mesh size $=1 \times 2 \mathrm{~mm}$ ). Ten tadpoles (initial mass of bullfrogs, $18.6 \pm 1.0 \mathrm{mg}$; of green frogs, $21.0 \pm 1.3 \mathrm{mg}$ ) were fed a $3: 1$ ration of rabbit chow: Tetramin fish flakes three times/wk at a rate of $6 \%$ of body mass/d. The laboratory light : dark schedule was $14: 10 \mathrm{~h}$.

The first experiment, conducted in 1994, quantified activity and spatial avoidance responses of green frogs and bullfrogs separately in the absence or presence of a single caged Umbra or Anax. We fed the predators 1-2 small tadpoles ( $\sim 50 \mathrm{mg}$ ) of the appropriate species three times/wk to maintain the predator cue in the water. We quantified the proportion of tadpoles active (moving) and occupying the predator half of the container by approaching a container and scan sampling (Altmann 1974). These observations were repeated 3540 times over a 5-wk period and included 0-2 observations/d. Examination of the data by weekly intervals provided no evidence of habituation to the predators over time.

A second laboratory experiment was conducted in
1995 to determine the behavioral responses of bullfrogs and green frogs to Lepomis. The experimental protocol was similar to the first experiment with the exceptions that we fed Lepomis 2 bullfrog larvae and 2 green frog larvae $(\sim 100 \mathrm{mg})$ three times per week, which better matched the experimental conditions of the field experiment that was run concurrently. The data consisted of 25 scan samples taken over a 9-d period to determine the proportion of tadpoles moving in each container and their spatial distribution.

For both experiments, we averaged the proportions of tadpoles active or on the predator side of the container over all observations for each tank. Means were arcsine-square-root transformed and analyzed with a MANOVA.

\section{Field experiment}

We conducted the field experiment in 1995 to determine whether the behavioral responses to the predators in the laboratory could be used to predict growth differences in a more natural setting and when the anuran larvae were competing. The field experiment was conducted in screened pens placed in the littoral zones of a 10-yr-old experimental pond that was raked clear of vegetation to provide a bare surface for the pens. Pens were $1.5 \times 1.0 \times 0.8 \mathrm{~m}$ and constructed of a 5 $\times 5$-cm lumber frame covered with $0.25-\mathrm{mm}$ nylon mesh to exclude predators present in the ponds. We laid out three spatial blocks of eight pens each. Once the pens were in place, $300 \mathrm{~g}$ of leaves (primarily Quercus spp.) were added to each pen to provide a substrate for periphyton growth.

Each pen was equipped with four predator cages. Three small cages constructed of $10 \times 11-\mathrm{cm}$ drain pipe and capped with $1.7-\mathrm{mm}$ fiberglass mesh were placed in the shallow end of each pen. A small cube of polystyrene was added so that the cages floated. The fourth cage was a large mesh bag $(1.0 \times 0.8 \times 0.3 \mathrm{~m})$ attached to the deep end of the pen. The small cages were designed to hold a single Anax and the large cage to hold either three Umbra or Lepomis. The density of predators $\left(1.5 / \mathrm{m}^{2}\right)$ was within natural predator densities of the two predators for which we have data (larval Aeshnid dragonfly density $=0.2-4.1 / \mathrm{m}^{2}$, Umbra density $=0.5-10.5 / \mathrm{m}^{2}$, Werner et al., unpublished data). The placement of Anax in the shallower water and the fish in the deeper water represents the depth distribution of these predators in natural ponds.

The experimental design consisted of three treatments lacking predators and five treatments containing different combinations of predators. The first three treatments were an additive competition design, with 50 bullfrog larvae alone $\left(33 / \mathrm{m}^{2}\right), 50$ green frog larvae alone $\left(33 / \mathrm{m}^{2}\right)$, or 50 bullfrog and 50 green frog larvae together; these treatments tested whether competition occurred between the two anuran species at these densities. We only have estimates of natural densities for green frogs; on the scale of an entire pond, green frog 
TABLE 1. MANOVA results ( $P$ values) from the two laboratory experiments investigating the effect of the absence or caged presence of Anax and Umbra (first experiment) or the effect of the absence or caged presence of Lepomis (second experiment) on the activity and spatial distribution of larval bullfrogs and green frogs reared separately.

\begin{tabular}{|c|c|c|c|}
\hline \multirow[b]{2}{*}{ Experiment } & \multirow{2}{*}{$\begin{array}{c}\text { Multivariate } \\
\text { test }\end{array}$} & \multicolumn{2}{|c|}{ Univariate tests } \\
\hline & & Activity & Spatial distribution \\
\hline \multicolumn{4}{|l|}{ First lab experiment } \\
\hline Anuran species & 0.006 & 0.004 & 0.230 \\
\hline Predator & $<0.001$ & $<0.001$ & $<0.001$ \\
\hline Anuran $\times$ Predator & 0.566 & 0.913 & 0.290 \\
\hline \multicolumn{4}{|l|}{ Second lab experiment } \\
\hline Anuran species & 0.011 & 0.035 & 0.094 \\
\hline Predator & 0.129 & 0.047 & 0.856 \\
\hline Anuran $\times$ Predator & 0.881 & 0.661 & 0.683 \\
\hline
\end{tabular}

densities range from 0.3 to $29.3 / \mathrm{m}^{2}$, whereas on a more localized scale within a pond, green frog densities can be as high as $350 / \mathrm{m}^{2}$. These data indicate that the densities we employed were within natural ranges (Werner et al., unpublished data). The five predator treatments each contained 50 bullfrog larvae and 50 green frog larvae. The treatments consisted of either three caged Lepomis (mean standard length $=75 \mathrm{~mm}$ ), three caged Umbra (mean standard length $=66 \mathrm{~mm}$ ), three caged Anax (penultimate instar), three caged Anax plus three caged Lepomis, or three caged Anax plus three caged Umbra. These predator treatments tested whether caged predators reduced growth of the anuran larvae and affected their competitive interactions.

Tadpoles and predators were added to the pens on 29 June 1995. Initial individual wet mass of bullfrogs was $20.5 \pm 1.5 \mathrm{mg}$ and of green frogs was $16.6 \pm 1.3$ $\mathrm{mg}$. Predators were fed three times per week to maintain the predator cue; each Anax was fed $\sim 100 \mathrm{mg}$ each of bullfrog and green frog larvae, while each fish was fed $\sim 50 \mathrm{mg}$ each of bullfrog and green frog larvae and $\sim 100 \mathrm{mg}$ of small earthworms. The earthworms were provided to supplement food and increase survivorship of the fish, since they do not consume these species of tadpoles as readily as other foods (Werner and McPeek 1994). The experiment was terminated on 27 July 1995. Upon termination, all tadpoles were sorted from the leaf litter, counted, and weighed. All unconsumed tadpoles that remained in the predator cages were also removed and counted.

ANOVAs were used to test for significant differences in survivorship and growth among treatments and between prey species. The survivorship and growth responses both met the assumptions of normal and homoscedastic residuals. One pen was a significant outlier $(P=0.05)$ using Dixon's (1950) test statistic, and this pen (Anax plus Umbra) was removed from the analysis. For significant treatment effects, means were compared using Fisher's test. The data for the mortality of tadpoles in the predator cages were heteroscedastic and could not be corrected by any transformation; these data were analyzed using the nonparametric KruskalWallis test.
To test whether predator-induced behavioral changes in the laboratory experiment were associated with tadpole performance in the field experiment, we regressed growth in the field on the behavioral responses (activity and spatial avoidance) to the four predator treatments (no-predator, Anax, Lepomis, and Umbra) using growth data for the four treatments experiencing interspecific competition and the same four predators. Because behavioral responses were derived from two separate laboratory experiments conducted in two different years, the baseline activity of the two anurans in the absence of predators was different (possibly due to differences in experiment duration or differences in genetic composition in the two groups of hatchlings). To standardize Lepomis responses in the second experiment to the baseline behavior of the first experiment, we divided the Lepomis responses by the no-predator, baseline response in the second experiment and then multiplied this quotient by the no-predator, baseline response in the first laboratory experiment.

\section{RESULTS}

\section{Laboratory experiments}

The two laboratory experiments demonstrated that bullfrog and green frog larvae responded to the presence of predators both through activity reduction and spatial avoidance (Table 1). The presence of caged $U m$ bra caused a $4-6 \%$ reduction in absolute activity in both anuran species (Fig. $1, P=0.040$ ), while the presence of Anax caused an $8-13 \%$ reduction in activity $(P=0.00001)$. Lepomis had no effect on activity of either species. Bullfrogs were consistently more active than green frogs in all treatments; there were no interactions.

In contrast, the anuran species did not differ in spatial distribution. Both exhibited a moderate spatial response (5-12\% avoidance) to the presence of caged Umbra (Fig. 2, $P=0.014$ ), and a strong response (15$30 \%$ avoidance) to the presence of $\operatorname{Anax}(P<0.00001)$. Lepomis had no effect on the spatial distribution of either anuran species. 


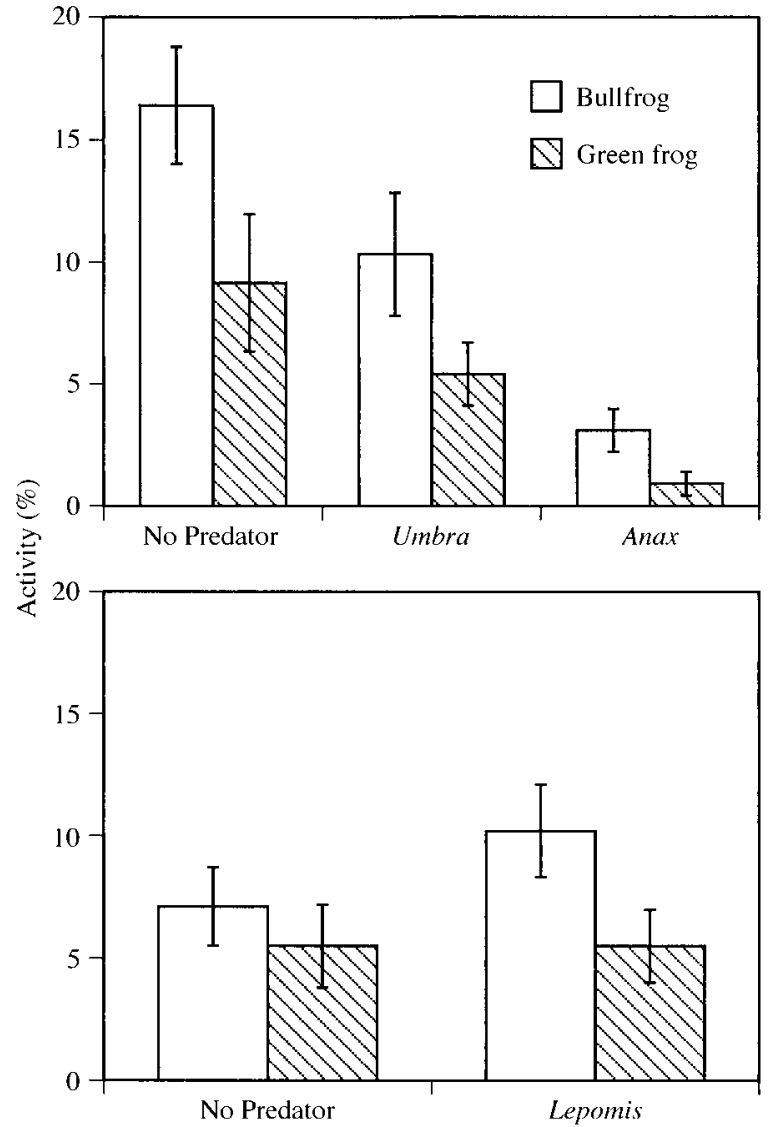

FIG. 1. Percent activity (mean $\pm 1 \mathrm{SE}$ ) of bullfrogs and green frogs that were reared separately in a series of laboratory experiments in the presence of no predators, caged Umbra, and caged Anax (upper panel), and in the presence of no predator and caged Lepomis (lower panel). Responses are based on the means of 25-40 observations of 10 tadpoles per replication.

\section{Field experiment}

Survivorship did not differ among treatments in the field experiment, but growth did (Table 2, Fig. 3). The changes in growth among treatments were relatively

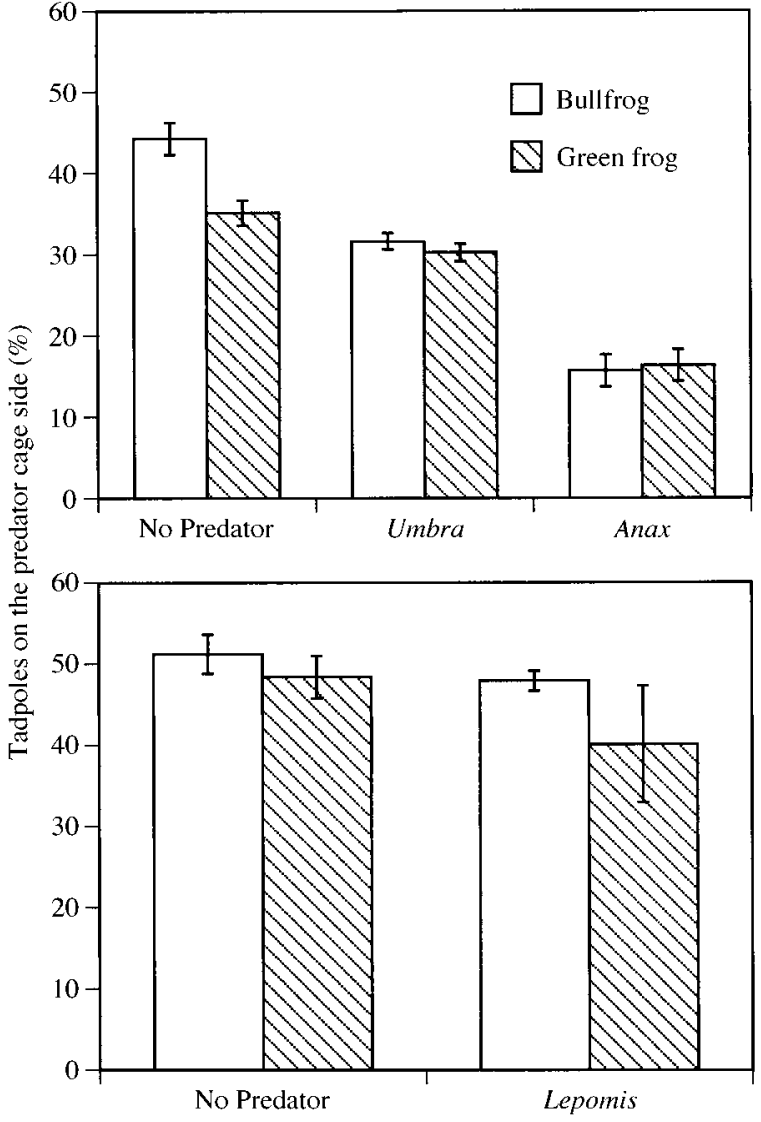

FIG. 2. Spatial avoidance (mean $\pm 1 \mathrm{SE}$ ) of bullfrogs and green frogs reared separately in a series of laboratory experiments in the presence of no predators, caged Umbra, and caged Anax (upper panel), and in the presence of no predator and caged Lepomis (lower panel). Responses are based on the means of 25-40 observations of 10 tadpoles per replication.

symmetrical for the two prey species (no significant interaction). For both anurans, the greatest growth occurred when alone. The addition of interspecific competitors reduced bullfrog growth by $37 \%$ and green frog

TABle 2. MANOVA results ( $P$ values) from the field experiment investigating the effect of blocks and treatments (see Materials: Field experiment for the list of eight treatments) on the survival and growth of larval bullfrogs and green frogs reared separately, together, and together under five different caged predator treatments.

\begin{tabular}{|c|c|c|c|c|}
\hline Treatment effects & df & Mean square & $F$ & $P$ \\
\hline \multicolumn{5}{|l|}{ Survival } \\
\hline Block & 2 & 0.017 & 1.19 & 0.321 \\
\hline Treatment & 6 & 0.010 & 0.72 & 0.634 \\
\hline Prey species & 1 & 0.001 & 0.08 & 0.786 \\
\hline Treatment $\times$ Prey species & 6 & 0.006 & 0.44 & 0.847 \\
\hline Error & 24 & & & \\
\hline \multicolumn{5}{|l|}{ Growth } \\
\hline Block & 2 & 2.7 & 1.8 & 0.190 \\
\hline Treatment & 6 & 26.0 & 16.9 & $<0.001$ \\
\hline Prey species & 1 & 46.6 & 30.3 & $<0.001$ \\
\hline Treatment $\times$ Prey species & 6 & 2.18 & 1.4 & 0.248 \\
\hline Error & 24 & & & \\
\hline
\end{tabular}


FIG. 3. Growth rates (mean $\pm 1 \mathrm{SE}$ ) of bullfrog and green frog larvae in field pens when reared alone, when reared together ("both"), and when reared together in the presence of caged Lepomis (L), Umbra (U), and Anax (A).

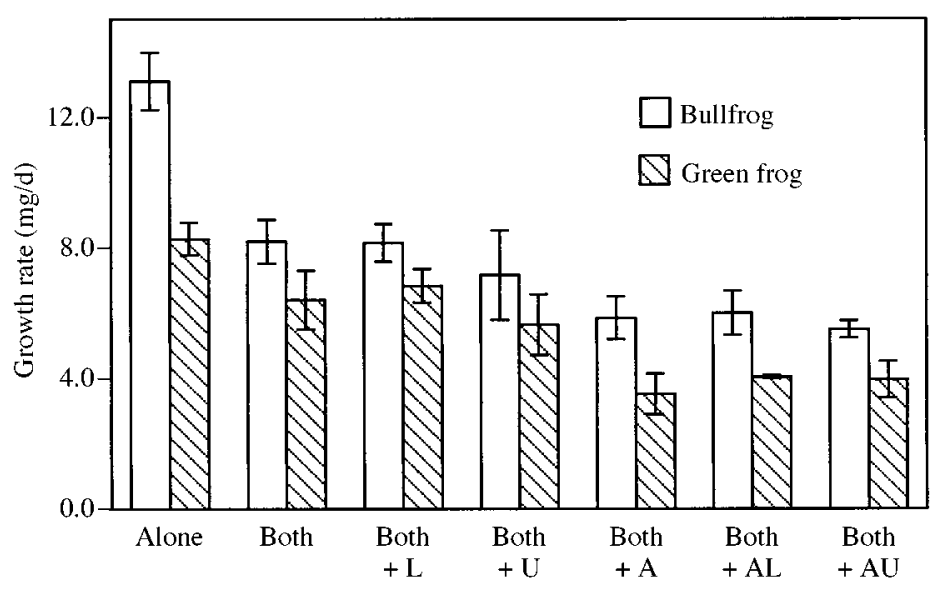

growth by $23 \%(P<0.001)$. The addition of caged Lepomis or Umbra to the bullfrog-green frog competition treatment did not affect growth of either species ( $P=0.791$ and $P=0.223$, respectively). However, predator treatments containing Anax exhibited reduced growth rates compared to the no-predator, competition treatment $(P<0.007)$; bullfrog growth was reduced $30 \%$, and green frog growth was reduced $40 \%$. Growth in the presence of Lepomis and Umbra did not differ $(P=0.142)$, growth in the presence of Lepomis was greater than all three treatments containing Anax $(P<$ $0.005)$, and growth in the presence of Umbra was nearly greater than the three treatments containing Anax $(P$ $\leq 0.07)$. The three treatments containing Anax did not differ from each other $(P>0.6)$.

Activity and spatial responses to the different predators in the laboratory were highly correlated with growth rates in the field (Table 3, Fig. 4). The predator treatments that caused the greatest reduction in activity and greatest spatial avoidance in the laboratory also caused the greatest reduction in growth in the field (Table 3).

The unconsumed tadpoles that remained in the predator cages provided additional evidence concerning the relative risk posed by each of the predators (Fig. 5). All of the tadpoles died in the Anax cages. In contrast,

TABLE 3. Linear regression results comparing laboratoryderived behavioral responses under four different predator treatments to field-derived growth rates under the same treatments.

\begin{tabular}{lcc}
\hline \hline \multicolumn{1}{c}{ Response } & $R^{2}$ & $P$ \\
\hline Bullfrog activity & 0.966 & 0.017 \\
Green frog activity & 0.992 & 0.004 \\
Bullfrog spatial distribution & 0.989 & 0.006 \\
Green frog spatial distribution & 0.876 & 0.064 \\
\hline
\end{tabular}

Notes: Decreased activity induced by the different predators in the laboratory was related to decreased growth in the field experiment. Likewise, increased spatial avoidance of the predator in the laboratory experiment was related to decreased growth in the field experiment.
$66 \%$ of bullfrogs and green frogs died in the Umbra cages, while $30 \%$ of bullfrogs and green frogs died in the Lepomis cages. These three mortality rates differed significantly (bullfrogs, $H_{2}=17.9, P=0.0001$; green frogs $\left.H_{2}=18.2, P=0.001\right)$.

\section{DISCUSSION}

The laboratory experiment demonstrated that the two anuran species exhibited prey- and predator-specific behavioral phenotypes. Activity and spatial responses in the bullfrog and green frog larvae were minor when with Lepomis, increased in strength with Umbra, and were quite strong with Anax. Thus, it appears that larval anurans can discriminate among species of predators. In this experiment, we cannot rule out the possibility that predators produced different amounts of a single chemical cue, as opposed to unique cues that differentiate each predator. However, other experiments on larval anurans suggest that the latter is indeed the case (Relyea, unpublished manuscript).

The behavioral responses were related to the risk posed by the different predators. Anax induced the strongest behavioral responses, and larval odonates are voracious predators of anuran larvae (Chovanec 1992, Azevedo-Ramos et al. 1992, Werner and McPeek 1994; Relyea, unpublished manuscript). In comparison, Umbra and Lepomis caused successively weaker behavioral responses, and both fish pose a lower risk to bullfrogs and green frogs because these anurans are somewhat unpalatable to fish (Kruse and Francis 1977, Petranka et al. 1987, Kats et al. 1988, Werner and McPeek 1994; Relyea, unpublished manuscript). The mortality of bullfrogs and green frogs in the predator cages provides further evidence of this relationship (Fig. 5); the highest mortality occurred in the Anax cages, with successively lower mortality in Umbra and Lepomis cages, respectively. This direct relationship between magnitude of antipredator response and predation risk has been observed frequently in a wide range of taxa (Sih 1987). 


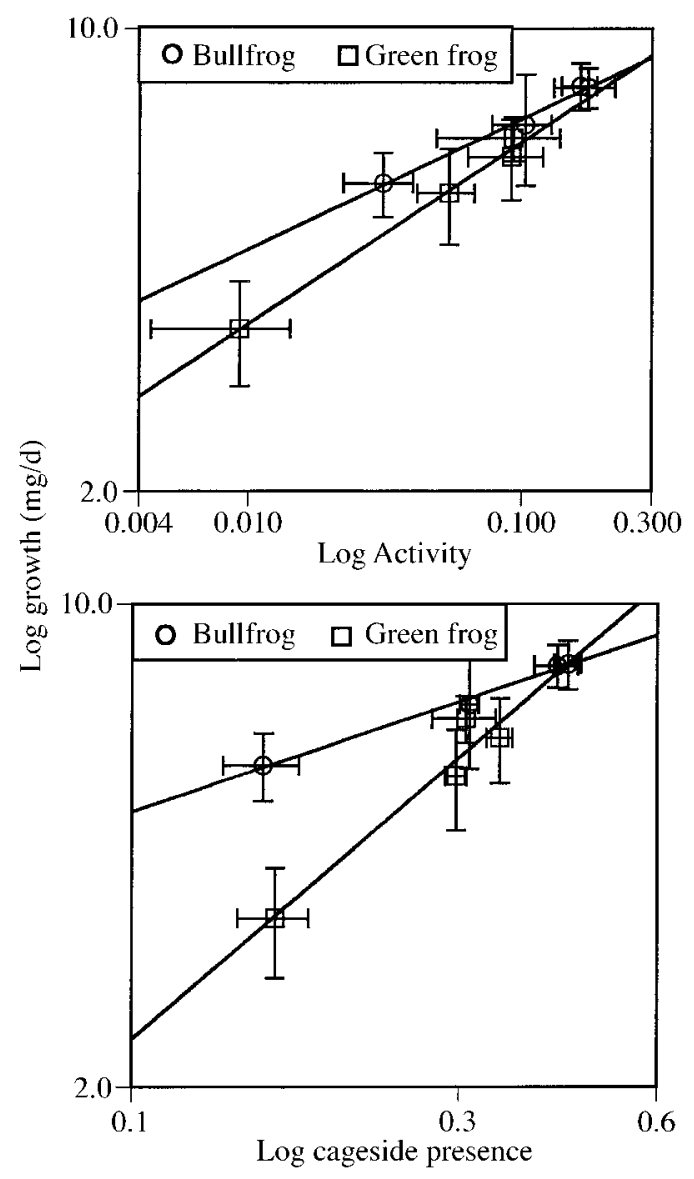

FIG. 4. The positive linear regressions of relative growth rates on activity (upper panel) and spatial avoidance (lower panel) in the field experiment in the presence of four different predator environments. Means \pm 1 SE are plotted. The behavioral responses were based on observations from laboratory experiments in which prey species were reared separately, whereas the growth responses were based on observations in a field experiment in which the prey species were reared together.

Predator-induced changes in prey behavior should affect prey growth. Higher activity often results in greater resource acquisition and competitive ability at the cost of increased risk of predation; thus, many taxa reduce activity when predators are present (Sih 1987, Lima and Dill 1990, Werner 1992, Werner and Anholt 1993). In the laboratory experiment, bullfrogs were always more active than green frogs. Thus, one would predict that bullfrogs would grow faster than green frogs under all field treatments, but that both species would exhibit successively lower growth in the $L e$ pomis, Umbra, and Anax treatments, respectively.

Similarly, increased spatial avoidance of predators also should cause reduced growth in the field, because resources near the predator become unavailable. Spatial avoidance of predators is common and often leads to reduced growth in prey (Sih 1980, 1982, Werner et al. 1983, Fraser and Huntingford 1986, Holomuzki 1986,
Sih 1987, Lima and Dill 1990, Skelly and Werner 1990, Turner and Mittlebach 1990, Persson and Eklöv 1995). We observed increasing spatial avoidance of both anurans in the laboratory in the Lepomis, Umbra, and Anax treatments, respectively, but found no differences in how the two anuran species responded to the treatments, which supports the earlier results of Werner (1991). Thus, based upon the spatial avoidance results, one would expect successively lower growth in the Lepomis, Umbra, and Anax treatments, respectively, but no growth differences between the two anurans within any of these treatments.

The behavioral responses of the anuran larvae in the laboratory were highly correlated with growth in the field. Lepomis induced no change in activity or spatial distribution in the laboratory, and growth was unaffected in the field. Umbra induced moderate reductions in activity in both prey species in the laboratory and moderate, although nonsignificant, reductions in growth in the field. Anax induced the strongest activity and spatial responses and the strongest growth reductions in the field. Other studies have demonstrated that the presence of a predator can alter growth in the field (Skelly 1992, Schmitz et al. 1997); the current study suggests that this effect varies among predator species and, in our case, may be described as a log-linear function of activity and spatial responses (Fig. 4).

The differences in growth between the two anurans

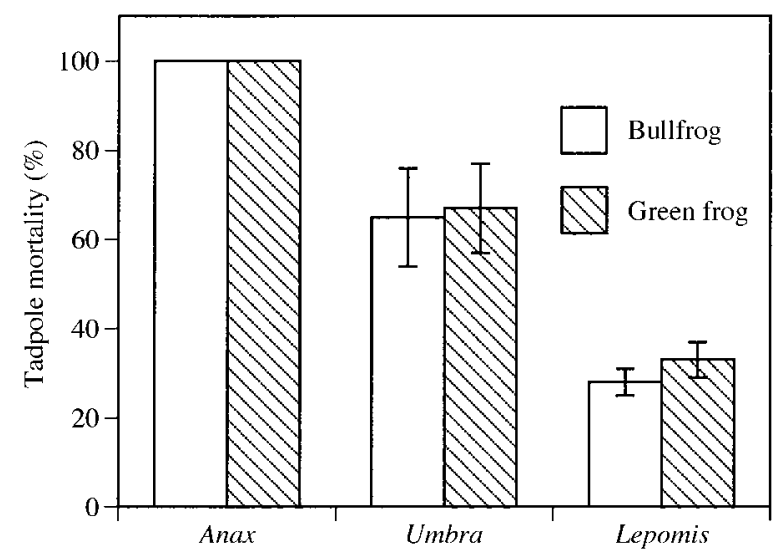

FIG. 5. The mortality percentages (mean $\pm 1 \mathrm{SE}$ ) of bullfrog and green frog tadpoles from the predator cages containing either Anax alone, Umbra alone, or Lepomis alone. Mortality was based on the number of animals recovered at the end of the field experiment divided by the number of animals fed to the predators in the cages. We do not have the data to ascertain how much of the anuran mortality in the predator cages can be attributed to starvation, but our observations of this and other experiments (Werner 1991, Werner and Anholt 1996, Peacor and Werner 1997) indicate that Anax almost always consume all tadpoles placed into their cages within $2 \mathrm{~d}$ of feeding, whereas tadpoles in the fish cages were not readily consumed, and some of the observed mortality could be attributed to starvation. 
in the field were likely due to differences in activity rather than spatial distribution. Bullfrogs exhibited higher activity than green frogs, and this may account for their higher growth (Morin 1983, Werner 1991, Werner and Anholt 1993). In contrast, bullfrog spatial distribution did not differ from that of green frogs; thus, spatial distribution cannot account for the differences in growth between the two anurans. We cannot attribute the reduced growth within species across treatments, however, to just one of the behaviors; both activity and spatial responses correlated well with growth. In fact, the two responses may reinforce each other in reducing growth in the presence of predators.

The field experiment also demonstrated that the growth of bullfrogs and green frogs in the presence of Anax plus Lepomis or Anax plus Umbra was not different from their growth in the presence of Anax alone. This suggests that the behavioral responses of the prey in these treatments also did not differ-that is, the anurans were simply responding to the riskiest predator, Anax. There are few comparative data on the responses of prey to the simultaneous presence of multiple predators. Eklöv and Werner (unpublished manuscript) found that uncaged dragonfly larvae (offering both chemical and visual cues) caused a large reduction in bullfrog activity; however, in treatments where Lepomis also were added, the dragonfly larvae moved less and caused less mortality, and the bullfrogs reduced activity less than when Anax was the sole predator. Thus, in cases where the addition of a second predator can alter the cues produced by the first predator, predation risk on the prey may increase or decrease (Soluk and Collins 1988, Huang and Sih 1990, 1991, Matsuda et al. 1993, Soluk 1993, Wissinger and McGrady 1993; Eklöv and Werner, unpublished manuscript). Because our predators were caged, it is unlikely that the addition of a second predator had an impact on cues presented to the prey by the first predator. In this case, prey may simply adjust their response to the riskiest predator.

In the field experiment, the two anurans had strong competitive effects on each other; the growth rate of bullfrogs declined $37 \%$, while that of the green frogs declined $23 \%$ compared to the single-species controls. It has been repeatedly shown that bullfrog and green frog larvae compete under a range of conditions, though the symmetry of the interaction appears to depend on experimental conditions (e.g., see Werner 1991 [8-L laboratory containers], Werner 1994 [pens in experimental ponds], and Werner and Anholt 1996 [1300-L pond mesocosms]).

Behavioral changes due to the presence of the predators may influence these competitive relations. In the presence of two of the predators, Lepomis and Umbra, the competitive relations remained similar to those in the absence of predators. Lepomis had no effect on behavior and thus would not be expected to alter competitive relations. The presence of Umbra decreased activity, and therefore growth rates, moderately in both anurans; the proportionate decline in activity was similar in the two anurans, and therefore the relative growth responses were similar to the no-predator treatment. In contrast, there is a suggestion of an alteration in relative competitive relations in the presence of Anax that is correlated with a disproportionate change in activity of the two species in the presence of Anax. The bullfrog: green frog activity ratio was 3.3 in the presence of Anax, compared to 1.8-1.9 in the absence of Anax. Correspondingly, the ratio of growth rates of the two species averaged across treatments lacking Anax $(1.28 \pm 0.11)$ was nearly different from the ratio of all treatments containing Anax $(1.54 \pm 0.09, P=0.08)$. This result is in accord with a previous laboratory study where Werner (1991) found that the ratio of bullfrog: green frog activity was 1.4 in the absence of Anax and 2.4 in the presence of Anax and that the bullfrog obtained proportionately more of the resources in the presence of Anax (see also Peacor and Werner 1997). There are several processes possibly contributing to the effect of Anax on competitive relations in this experiment. First, the direct effect of the presence of Anax on activity levels of the anurans will alter the proportion of shared resources obtained by the two species. Second, there may be trait-mediated indirect effects though resources that contribute to the greater resource acquisition of the bullfrog with Anax. We have evidence from other experiments that trait-mediated indirect effects can be important (Werner 1991, Peacor and Werner 1997). This analysis again points to the critical importance of activity level in influencing the growth performance in the field. None of the alterations in competitive relations is associated with spatial responses, since the latter were similar across all predator treatments.

This study illustrates how individual traits (behavior, in this case) measured under controlled laboratory conditions can be quantitatively related to species performance (growth rate) in the field. Phenotypically plastic responses allow us to examine the consequences of possessing different trait values to performance in species interactions. Developing the relationships between trait values and performance will permit a more mechanistic understanding of species interactions and enable a priori predictions of the consequences of these interactions. When the traits involved are common to many species (e.g., activity), we may be able to generalize these predictions to other taxa.

\section{ACKNOWLEDGMENTS}

We thank Peter Eklöv, Andy McCollum, Scott Peacor, Jeff Quakenbush, Josh Van Buskirk, Amy Yarger, and Kerry Yurewicz for assistance with the field work and Ronald Nussbaum and Richard Alexander for providing access to the E. S. George Reserve. We also thank Scott Peacor, Oswald Schmitz, and Kerry Yurewicz for their comments on this manuscript. This work was supported by University of Michigan research grants and NSF grants DEB-9119948 and DEB9408397 


\section{Literature Cited}

Altmann, J. 1974. Observational study of behavior: Sampling methods. Behaviour 49:227-267.

Azevedo-Ramos, C., M. Van Sluys, J. Hero, and W. E. Magnusson. 1992. Influence of tadpole movement on predation by odonate naiads. Journal of Herpetology 26:335-338.

Chovanec, A. 1992. The influence of tadpole swimming behaviour on predation by dragonfly nymphs. Amphibia-Reptilia 13:341-349.

Collins, J. P., and H. M. Wilbur. 1979. Breeding habits and habitats of the amphibians of the Edwin S. George Reserve, Michigan, with notes on the local distribution of fishes. Occasional Papers Museum of Zoology, University of Michigan, Number 686:1-34.

Dixon, W. J. 1950. Analysis of extreme values. Annals of Mathematical Statistics 21:488-506.

Fraser, D. F, and F. A. Huntingford. 1986. Feeding and avoiding predation hazard: the behavioral response of prey. Ethology 73:56-68.

Holomuzki, J. R. 1986. Predator avoidance and diel patterns microhabitat use by larval tiger salamanders. Ecology 67: 737-748.

Huang, C., and A. Sih. 1990. Experimental studies on behaviorally mediated, indirect interactions through a shared predator. Ecology 71:1515-1522.

Huang, C., and A. Sih. 1991. Experimental studies on direct and indirect interactions in a three trophic level stream system. Oecologia 85:530-536.

Kats, L. B., J. W. Petranka, and A. Sih. 1988. Antipredator defenses and the persistence of amphibian larvae with fishes. Ecology 69:1865-1870.

Kruse, K. C., and M. G. Francis. 1977. A predation deterrent in larvae of the bullfrog, Rana catesbeiana. Trans. Am. Fish. Soc. 106:248-252.

Lima, S. L., and L. M. Dill. 1990. Behavioral decisions made under the risk of predation: a review and prospectus. Canadian Journal of Zoology 68:619-640.

Matsuda, H., P. A. Abrams, and M. Hori. 1993. The effect of adaptive anti-predator behavior on exploitative competition and mutualism between predators. Oikos 68:549559

McCollum, S. A., and J. Van Buskirk. 1996. Costs and benefits of a predator-induced polyphenism in the gray treefrog Hyla chrysocelis. Evolution 50:583-593.

Morin, P. J. 1983. Predation, competition, and the composition of larval anuran guilds. Ecological Monographs 53 : 119-138.

Peacor, S. D., and E. E. Werner. 1997. Trait-mediated indirect interactions in a simple aquatic food web. Ecology 78: $1146-1156$.

Persson, L., and P. Eklöv. 1995. Prey refuges affecting interactions between piscivorous perch and juvenile perch and roach. Ecology 1:70-81.

Petranka, J. W., L. B. Kats, and A. Sih. 1987. Predator-prey interactions among fish and larval amphibians: use of chemical cues to detect predatory fish. Animal Behavior 35:420-425.

Schmitz, O. J, A. P. Beckerman, and K. M O’Brien. 1997. Behaviorally mediated trophic cascades: effects of predation risk on food web interactions. Ecology 78:1388-1399.

Schoener, T. W. 1986. Mechanistic approaches to community ecology: a new reductionism? American Zoologist 26:81106.

Sih, A. 1980. Optimal behavior: can foragers balance two conflicting demands? Science 210:1041-1043.

. 1982. Foraging strategies and the avoidance of predation by an aquatic insect, Notonecta hoffmanni. Ecology 63:786-796.

1987. Predators and prey lifestyles: an evolutionary and ecological overview. Pages 203-224 in W. C. K. Sih, editor. Predation: direct and indirect impacts on aquatic communities. University Press of New England, Hanover, New Hampshire, USA.

Skelly, D. K. 1992. Field evidence for a cost of behavioral antipredator response in a larval amphibian. Ecology 73: 704-708.

Skelly, D. K., and E. E. Werner. 1990. Behavioral and lifehistorical responses of larval American toads to an odonate predator. Ecology 71:2313-2322.

Soluk, D. A. 1993. Multiple predator effects: predicting combined functional response of stream fish and invertebrate predators. Ecology 74:219-225.

Soluk, D. A., and N. C. Collins. 1988. Synergistic interactions between fish and stoneflies: facilitation and interference among stream predators. Oikos 52:94-100.

Tilman, D. 1987. The importance of the mechanisms of interspecific competition. American Naturalist 129:769-774.

Turner, A. M., and G. G. Mittelbach. 1990. Predator avoidance and community structure: interactions among piscivores, planktivores, and plankton. Ecology 71:2241-2254.

Wellborn, G. A., D. K. Skelly, and E. E. Werner. 1996. Mechanisms creating community structure across a freshwater habitat gradient. Annual Review of Systematics and Evolution 27:337-363.

Werner, E. E. 1991. Nonlethal effects of a predator on competitive interactions between two anuran larvae. Ecology 72:1709-1720.

1992. Individual behavior and higher-order species interactions. American Naturalist 140:S5-S32.

- 1994. Ontogenetic scaling of competitive relations: size-dependent effects and responses in two anuran larvae. Ecology 75:197-213.

. 1998. Ecological experiments and a research program in community ecology. Pages 3-26 in W. Resetarits and J. Bernardo, editors. Experimental ecology: issues and perspectives. Oxford University Press, Oxford, UK.

Werner, E. E., and B. R. Anholt. 1993. Ecological consequences of the trade-off between growth and mortality rates mediated by foraging activity. American Naturalist 142: 242-272.

Werner, E. E., and B. R. Anholt. 1996. Predator-induced behavioral indirect effects: consequences to competitive interactions in anuran larvae. Ecology 77:157-169.

Werner, E. E., J. F. Gilliam, D. J. Hall, and G. G. Mittelbach. 1983. An experimental test of the effects of predation risk on habitat use in fish. Ecology 64:1540-1548.

Werner, E. E., and M. A. McPeek. 1994. Direct and indirect effects of predators on two anuran species along an environmental gradient. Ecology 75:1368-1382.

Wissinger, S., and J. McGrady. 1993. Intraguild predation and competition between larval dragonflies: direct and indirect effects on shared prey. Ecology 74:207-218. 